\title{
La creatividad en las redes sociales en tiempos de crisis: Alternativa para la comunicación del Tercer Sector en España
}

\author{
Creativity in social networks in times of crisis: Alternative for the \\ communication of the Third Sector in Spain
}

Isidoro ARROYO ALMARAZ

Universidad Rey Juan Carlos isidoro.arroyo@urjc.es

Miguel BAÑOS GONZÁLEZ Universidad Rey Juan Carlos miguel.banos@urjc.es

Recibido: 10 de septiembre 2013 Aceptado y Publicado: 24 de noviembre de 2013

\begin{abstract}
Resumen
Las organizaciones del Tercer Sector tienen entre sus objetivos comunicar para transmitir sus valores a la sociedad. La profunda crisis que en los últimos años estamos viviendo en España ha hecho que las redes de la web 2.0 sean cada vez más utilizadas por organizaciones del Tercer Sector.

La comunicación de estas organizaciones será más eficiente en tanto en cuanto su creatividad vaya dirigida a desarrollar la inteligencia emocional de sus públicos; es decir, desde el momento en el que difundan y proyecten simpatía y empatía por los lugares comunes de las emociones y sentimientos colectivos: la solidaridad, la compasión y, en algún caso, combatir la indiferencia o despertar la indignación.

Los mensajes que únicamente pretendían sensibilizar a la población a través de comunicaciones que pronosticaban gravísimos males para despertar la compasión y, a través de ella, la solidaridad solamente han servido para estimular el voyeurismo que, por
\end{abstract}


saturación de imágenes de dolor, ha vacunado a los públicos acostumbrándoles al dolor ajeno que se convierte en tolerable cuando son los demás los que lo sufren. $Y$ esta tolerancia se incrementa cuanto mayor sea la distancia que nos separa de quienes sufren, de acuerdo con el imperativo que establece que "Amarás al cercano y rechazarás al lejano".

La comunicación de estas organizaciones deben planificarse de acuerdo a unos objetivos de desarrollo de la inteligencia emocional que contemple sentimientos auténticos. Se trata de presentar situaciones que muevan a la acción. Es decir posicionar sus mensajes desde una óptica optimista que considere que el mundo puede ser un lugar mejor, por tanto considerar el optimismo como posicionamiento moral, tal como lo proclama Mark Stevenson (2011), "como imperativo moral" porque si no estamos preparados para imaginar un mundo mejor, condenamos al mundo a ser peor.

\section{Summary}

Third Sector organizations have among their objectives to communicate to transmit their values to society. The deep crisis that we are experiencing in Spain in recent years has made web 2.0 networks increasingly used by Third Sector organizations.

The communication of these organizations will be more efficient insofar as their creativity is aimed at developing the emotional intelligence of their audiences; that is, from the moment they spread and project sympathy and empathy for the commonplaces of collective emotions and feelings: solidarity, compassion and, in some cases, combat indifference or arouse indignation.

The messages that only tried to sensitize the population through communications that predicted very serious evils to awaken compassion and, through it, solidarity have only served to stimulate voyeurism that, due to saturation of images of pain, has vaccinated the public accustoming them to the pain of others that becomes tolerable when it is others who suffer. And this tolerance increases the greater the distance that separates us from those who suffer, in accordance with the imperative that establishes that "You will love the near and reject the distant."

The communication of these organizations must be planned according to objectives for the development of emotional intelligence that includes authentic feelings. It is about presenting situations that move to action. That is to say, position their messages from an optimistic perspective that considers that the world can be a better place, therefore consider optimism as a moral position, as proclaimed by Mark Stevenson (2011), "as a 
moral imperative" because if we are not prepared to imagine a better world, we condemn the world to be worse.

Palabras claves: Redes sociales, Crisis, Creatividad, Organizaciones del tercer sector; Comunicación.

Key Words: Social networks, Crisis, Creativity, Third sector organizations, Communication

\section{Desarrollo}

La herramienta para generar estas emociones optimistas es la creatividad. A través de ella, las organizaciones del Tercer Sector pueden desarrollar comunicaciones capaces de motivar a los sujetos para que actúen (Rodrigo Martín y López López, 2012), abriendo caminos hasta el momento impensables (Moreno, 2008). Pero el reto de la creatividad obliga a ser más flexibles y, sobre todo, deshacer caminos conocidos. Las situaciones difíciles y/o extremas favorecen los procesos creativos e incrementan el desarrollo de facultades mentales creativas.

Un ejemplo de ello lo tenemos en la organización "Tenemos SIDA". Desde hace tiempo, esta entidad aconseja y forma a instituciones, empresas y entidades para que aprendan a mirar de otra manera más creativa para dar visibilidad al tema del VIH con motivo del día mundial de la vacuna contra el sida. "Nos sentamos a pensar. Escogimos un mensaje relacionado con la vacuna y lo dimos a conocer, con un coste prácticamente cero. Su página web pasó de las 300 a las 20.000 visitas", comenta Ismael Pantaleón; la creatividad "no es la solución para todo pero produce muchos beneficios" y hace posible montar acciones con bajo presupuesto y con una elevada repercusión.

Otro ejemplo más reciente lo tenemos en la campaña de Amnistía Internacional "Ropa comprometida 2013"; la organización ha creado una colección de 10 prendas de mujer, 
hombre y niño, inspiradas en casos reales de vulneración de derechos humanos, con las que se pretende concienciar a la sociedad sobre la tortura, la falta de libertad de expresión, la represión a la orientación sexual, la pena de muerte... Con la compra de cada prenda la persona colabora económicamente, se conciencia del problema y ayuda a difundir el mensaje solidario.

Pero para lograrlo es necesario ser más flexible y sobre todo "desaprender". Una vez más se cumple el viejo aforismo: "El hambre agudiza el ingenio" Las situaciones difíciles y/o extremas favorecen los procesos creativos e incrementan el desarrollo de facultades mentales creativas.

Hoy esa creatividad pasa por abrir nuevos caminos aplicando unas buenas dosis de las facultades mentales creativas. Entre otras, una gran tolerancia a la ambigüedad, autonomía e independencia de pensamiento, flexibilidad para adaptarse a las nuevas situaciones, capacidad de asumir riesgos y una fuerte motivación hacia el trabajo (Romo, 2009).

No hay duda de que, desde el origen mismo de la publicidad, sus profesionales han tenido una fuerte personalidad emprendedora capaz de aprovechar el poder de la comunicación para mejorar la sociedad.

Así lo manifestaron en sucesivas épocas grandes hombres del pensamiento y la práctica publicitaria como fueron Prat Gaballí en España, David Ogilvy en Gran Bretaña o Howard Gossage en Estados Unidos; para los que su mayor satisfacción profesional fue contribuir a través de la publicidad a grandes causas como la higiene, la lucha contra el cáncer o la protección del medioambiente.

Y otros muchos, a través de iniciativas tan distintas como la polémica exhibición de temas sociales realizada en campañas de publicidad gráfica encabezada por Oliviero Toscani en la década de 1990 en Italia, o la fundación de la red online Publicitarios sin Fronteras por iniciativa del argentino Guillermo Caro (Alvarado, 2012, 198). 
Para Antonio Caro Almela ${ }^{1}$ la tarea emprendedora pasaría también por este proceso de desaprender, de despojar a la publicidad de toda connotación comercial y devolverle su acepción comunicacional más pura la que hace referencia a publicitar en el sentido de "hacer algo público".

Y esta propuesta de una publicidad más comunicativa y menos comercial nos metería de lleno en el territorio de la publicidad social.

La crisis económica, los avances tecnológicos y especialmente los acaecidos en el panorama de los medios sociales con la explosión de las redes sociales, los cambios en los consumidores y en la sociedad, etc., están favoreciendo esta reflexión sobre las posibilidades de este cambio. Se habla ya de una postpublicidad, o de una publicidad conversacional, dialógica o publicidad interactiva. Es aquí donde centramos nuestra propuesta en el uso que se hace de esa publicidad dialógica a favor del cambio social.

Para ello se deben utilizar los múltiples formatos de comunicación que aporta la web 2.0 favoreciendo las comunicaciones horizontales a través de los blogs, y los perfiles en las grandes redes sociales: Facebook, Tuenti, YouTube, Twitter, etc.

Hemos observado en nuestras investigaciones que cada vez son más las organizaciones que utilizan estas herramientas dentro de sus estrategias de comunicación en la web 2.0 porque están tomando conciencia de que los proyectos de desarrollo implican la participación del público en las movilizaciones masivas y éstas no pueden congregarse si no hay una comunicación eficaz.

Veamos ahora los datos conseguidos a través del rastreo de las herramientas de la web 2.0 utilizadas por las ONGD calificadas por AECID y su porcentaje de uso sobre el total de 43 organizaciones calificadas:

\section{Facebook $81 \%$}

\footnotetext{
1 Afirmación realizada por el profesor Antonio Caro Almela en una de las sesiones del Máster en Comunicación con Fines Sociales que se imparte en el Campus de Segovia de la Universidad de Valladolid, el día 27 de enero de 2012 (citado por Alvarado, 2012).
} 
2. Twitter $58 \%$

3. Youtube $53 \%$

4. Flickr $46 \%$

5. Linkedln $41 \%$

6. Blog propio $27 \%$

7. Tuenti $25 \%$

8. Blogger $18 \%$

9. Slideshare $13 \%$

10. Wordpress $6 \%$

Hemos observado que cada vez son más las organizaciones que utilizan estrategias en la web 2.0 (Arroyo, Baños y Rodríguez, 2012) porque estas están tomando conciencia de que los proyectos de desarrollo implican la participación de los públicos en las movilizaciones masivas y estas no pueden ocurrir si no hay comunicación.

En todos estos formatos y/o canales es esencial, en primer lugar, la presencia del vídeo viral para ser compartido y comentado en las diferentes redes sociales y, en segundo lugar, saber cómo lo asimila y difunde el usuario, según se encuentre en una u otra red social.

Los vídeos consumidos en YouTube desde la ubicación España están más relacionados con la identidad cultural local, a pesar de que el internauta puede elegir entre un gran número de vídeos procedentes de todo el mundo. Por lo que lo local no solo no está en peligro, sino que puede convertirse en el pilar esencial de la comunicación a través de Internet. (Gallardo Camacho, y Alonso, 2012) que gracias a la geolocalización favorecida por la integración de GPS en los modernos smartphones podría multiplicar las relaciones directas entre los usuarios y los emisores.

Estos videos están siendo utilizados como uno de los motores de la industria publicitaria on-line gracias a su gran capacidad de segmentar a las audiencias y a su facilidad para 
medir el engagement con sus públicos. Además 2012 se convirtió en el año de la gran eclosión del Mobile Marketing en España.

YouTube es la cuarta web con mayor tráfico de visitas en España y la tercera en el mundo (Alexa, 2011). El 60 por ciento de los internautas españoles encuestados por el Interactive Advertising Bureau (2010) visita con regularidad YouTube. Esta red social de vídeos solo es superada por Facebook (el 89 por ciento la visita con regularidad), pero está por delante de Tuenti (44 por ciento), de MySpace y de Twitter (ambas con un 18 por ciento). Se utilizan YouTube y Vímeo fundamentalmente para promocionar los mensajes de las ONG a través de vídeos debido al bajo coste con el que pueden difundir sus objetivos, siempre buscando un efecto de viralidad a través de las llamadas técnicas de marketing WOM digital o "buzz marketing".

Nuestra propia investigación para el Ministerio de Economía y Competitividad (CSO200911203) dirigida a analizar los elementos formales de los mensajes audiovisuales utilizados en los vídeos emitidos por las Organizaciones sin ánimo de lucro, a través de YouTube, revela que estas organizaciones generan una comunicación previsible que tiende a estructuras homogéneas y fácilmente identificables en dos perfiles: Perfil de carácter más informativo (PI) y Perfil de carácter más persuasivo (PP) (Arroyo, Baños y Van Wyk, 2013).

Es, por tanto, un reto para las organizaciones del Tercer Sector, conscientes de la necesidad de enfrentarse a las nuevas situaciones con nuevas herramientas, aprovechar todas las ventajas de las redes sociales para difundir los sentimientos colectivos de solidaridad, compasión e indignación frente a los grandes retos que se le plantean a la humanidad en el siglo XXI: la defensa de los derechos humanos, la lucha contra la pobreza y el reparto justo de alimentos y la protección del medio ambiente.

\section{Bibliografía}

Alvarado López, M. a Cruz (2012). La publicidad en el marco de la comunicación para el desarrollo 
CIC Cuadernos de Información y Comunicación, vol. 17, 191-207.

Arroyo, I.; Baños, M. y Rodríguez, T. (2012). Modelo de investigación de las piezas audiovisuales de las organizaciones del tercer sector en redes sociales. En: MORAGAS, Miguel de; LÓPEZ, Bernat. y GARCÍA, Antonio. (eds.). Comunicación y Riesgo. Tarragona: Actas del Congreso AE-IC 2012, pp.1-18.

Arroyo Almaraz, I.; Baños González, M. y Van Wyk, C. (2013). Análisis de los mensajes audiovisuales del Tercer Sector en YouTube, en Revista Latina de Comunicación Social, . La Laguna (Tenerife): Universidad de La Laguna, páginas a recuperado el 29 de abril de 2013, de http://www.revistalatinacs.org/068/ DOI

Gallardo Camacho, J. y Alonso, A. J. (2012). El fenómeno 'glocal' en las redes sociales El caso YouTube España. Revista TELOS (Cuadernos de Comunicación e Innovación) no julio Septiembre. pp. $1 / 9$

Moreno, J. (2008.) La creatividad puede ayudar a las ONG a abrir caminos hasta el momento impensables Canalsolidario.org (disponible en: http://www.canalsolidario.org/noticia/lacreatividad-puede-ayudar-a-la..)

Rodrigo Martín, I. y López López, M. A. (2012). Creatividad y Crisis. Creatividad y Sociedad, vol. junio.

Romo, M. (2009): Pensamiento creador en tiempos de crisis. Encuentos Multidisciplinares, Vol 31. URL: multidisciplinares.org/Revistan\%BA31/Manuela_Romo_Santos.pdf] [http://www.encuentros21/01/2013).

Mark, S. (2011) Optimista por el futuro: Un hombre curioso propone responder a la pregunta: ¿Qué viene ahora? Galaxia Gutenberg-Círculo de Lectores: Madrid

\section{Fuentes documentales}

AA.VV. (2009) "Crisis y ONG: Desayunos CE | Compromiso Empresarial" disponible en: http://www.compromisoempresarial.com/ong/2009/06/crisis-y-ong-desayunos-ce/ 
APFOS (2012): Cambio de modelo de la ONG frente a la crisis: ¿alternativas? Canalsolidario.Org 25/10/2012 (disponible en: http://www.canalsolidario.org/noticia/cambio-de-modelo-de-laong-fre.)

EFE (2012): Las ONG han reducido plantillas y han tenido que reorientar sus prioridades por la crisis. 20minutos.es. 25/10/12. Recuperado http://www.20minutos.es/noticia/1545688/0/crisis-economica/obliga-ongs/reducir-plantillas/

Grupo GFK (2012): El 82\% de los europeos teme a la crisis económica y sus consecuencias. Estudio realizado para National Geographic Channel "Preparados para el fin del mundo", (NGC)instituto de investigación GfK Recuperado http://www.nationalgeographic.es/noticias/national-geographic-cha...82-de-los-europeosteme-a-la-crisis-economica-y-sus-consecuencias 25/10/12 00:20 Página 9 de 13

Jiménez, Miguel (2012): Ya hay más de dos millones de parados que no cobran ninguna prestación. EL PAÍS 5/11/2012.

Vera, Chema (2012): El reto de dirigir una ONG en tiempos de crisis. recuperado http://blogs.elpais.com/3500-millones/2012/09/el-reto-de-dirigir-una-o...y-la-necesaria-vuelta-alo-basico/ [consultado el 10 de abril de 2012

\section{Forma de citar este artículo en bibliografías}

ARROYO ALMARAZ, I. y BAÑOS GONZÁLEZ, M. (2013). "La creatividad en las redes sociales en tiempos de crisis: Alternativa para la comunicación del Tercer Sector en España" se encuentra publicado en Revista PANGEA (ISSN: 2172 - 3168); Año 2013, Nº 2, en páginas 118 a 126. Red Académica Iberoamericana de Comunicación. Recuperado el__ de __ de 2 ___ de: http://www.revistapangea.org 